\title{
Evolution of grain-to-grain second order internal stresses during long-term service in a dry-steam pipe steel
}

\author{
Gy. Gémes ${ }^{1}$, L. Balogh², T. Ungár ${ }^{2} *$ \\ ${ }^{1}$ AIB-Vincotte Hungary Kft., Dózsa György út 40, H-1071 Budapest, Hungary \\ ${ }^{2}$ Department of Materials Physics, Eötvös University Budapest, Hungary
}

Received 15 April 2009, received in revised form 12 November 2009, accepted 16 November 2009

\begin{abstract}
The lifetime of dry steam pipes in fossil fuelled power plants in the Central European region, especially in Hungary, is expected to be about 30 years. Besides gauge changes followed by metric controlling methods, the microstructure of the steel materials is also deteriorating due to operation at about $540{ }^{\circ} \mathrm{C}$ and at about 165 bar. High resolution X-ray line profile analysis reveals that large grain-to-grain, second-order residual internal stresses develop during the service period that finally, closer to the end of the expected life period of the materials, decrease strongly. The evolution of grain-to-grain internal stresses is explained on the basis of elastic anisotropy of steel, whereas the decrease of these internal stresses is attributed to the deterioration of the grain boundary structure by precipitate coarsening and void formation during operation of the dry steam pipes at $540{ }^{\circ} \mathrm{C}$ and 165 bar.
\end{abstract}

K e y w or d s: lifetime of dry-steam pipe steel, intergranular stresses, second-order stresses, grain-to-grain internal stresses, high resolution X-ray diffraction

\section{Introduction}

Power generation in Hungary is performed up to $60-65 \%$ in fossil fuelled 20 to 25 years old power plants. One of the key components of these power plant types is the dry-steam pipe system connecting the steam boiler to the steam turbine. In the major part of the Hungarian fossil fuelled power plants, the dry-steam pipes are prepared from the $12 \mathrm{H} 1 \mathrm{MF}$ type low-alloy creep resistant steel, which has mainly been fabricated in the former Soviet Union. The key components of these power plants, including the dry-steam pipe systems, were usually designed for 30 years. Safety and reliability measures, however, require continuous inspection and examination of the critical components of power plants. The most common follow up methods are either mechanical investigations for checking gauges and sizes of the different components [1], or metallographic procedures for the characterization of the state of the materials [24]. The main reason of deterioration of the dry-steam pipe system is creep [1-4]. Accordingly, any method that can be used to characterize the microstructure of the materials can be considered as relevant for follow up and/or checking of remnant lifetime of dry-steam pipe system in a power plant. In the present work the method of high-resolution X-ray line profile analysis is used to characterize the microstructure of dry-steam pipe materials during long-term service in terms of the evolution of intergranular II. order residual internal stresses.

\section{Experimental}

Low alloy high-strength and high creep-resistant steel specimens were investigated. One specimen was prepared from the as-received state of the dry-steam pipe: initial-state (ISt). Two further specimens were taken from the tube materials after $154.530 \mathrm{~h}$ and $220.384 \mathrm{~h}$ in service, respectively. The specimens are denoted as: ISt, $154.530 \mathrm{~h}$ and $220.384 \mathrm{~h}$, respectively. In each state of the materials two specimens were prepared: one from the inner and one from the outer surface region of the tube, where the tube was of $38 \mathrm{~mm}$ wall thickness and $325 \mathrm{~mm}$ of outer diameter.

*Corresponding author: tel./fax: +3613722801/11; e-mail address: ungar@ludens.elte.hu 
Table 1. Constitution of the dry-steam-pipe steel materials

\begin{tabular}{cccccccccc}
\hline $\begin{array}{c}\mathrm{C} \\
\text { (wt.\%) }\end{array}$ & $\begin{array}{c}\mathrm{Si} \\
\text { (wt.\%) }\end{array}$ & $\begin{array}{c}\mathrm{Mn} \\
\text { (wt.\%) }\end{array}$ & $\begin{array}{c}\mathrm{Cr} \\
\text { (wt.\%) }\end{array}$ & $\begin{array}{c}\mathrm{Mo} \\
\text { (wt.\%) }\end{array}$ & $\begin{array}{c}\mathrm{V} \\
\text { (wt.\%) }\end{array}$ & $\begin{array}{c}\mathrm{Cu} \\
\text { (wt.\%) }\end{array}$ & $\begin{array}{c}\text { P max. } \\
\text { (wt.\%) }\end{array}$ & $\begin{array}{c}\mathrm{S} \\
\text { (wt.\%) }\end{array}$ & Fe \\
\hline $0.08-0.15$ & $0.17-0.37$ & $0.40-0.70$ & $0.90-1.20$ & $0.25-0.35$ & $0.15-0.30$ & 0.20 & 0.025 & 0.025 & balance to $100 \%$ \\
\hline
\end{tabular}

The chemical composition of the specimens is given in Table 1 . The initial state was prepared by normalizing from $950-980^{\circ} \mathrm{C}$ and tempered at $720-750^{\circ} \mathrm{C}$, and cooled in air. The operation conditions were at $540^{\circ} \mathrm{C}$ and at a pressure of $165 \mathrm{bar}$. The $10 \times 10 \times 2 \mathrm{~mm}^{3}$ size specimens were cut from the pipe materials by careful forging under cooling liquid. For the sake of removing any damaged surface layer, the specimens were mechanically polished and finally electropolished.

X-ray diffraction patterns were measured by two different X-ray diffractometers: (i) once by a Philips $\mathrm{X}$ 'Pert powder diffractometer using $\mathrm{Cu} \mathrm{K} \alpha$ radiation and pirolithic graphite secondary monochromator, and (ii) once by a special high resolution double crystal diffractomer $[5,6]$ using $\mathrm{Co} \mathrm{K} \alpha_{1}$ radiation. In latter the fine-focus cobalt anode was operated at $35 \mathrm{kV}$ and $30 \mathrm{~mA}$. The symmetrical (220) reflection of a plane Ge monochromator was used to eliminate the $\mathrm{K} \alpha_{2}$ component of Co radiation. The cross section of the beam impinging the specimen was about $0.2 \times 2 \mathrm{~mm}^{2}$. Diffraction patterns were measured with imaging plates (IP) $220 \mathrm{~mm}$ long and $100 \mathrm{~mm}$ wide, placed in IP holders curved to $200 \mathrm{~mm}$ radius. Two-curved IPs covered the $2 \theta$ angular range between 40 and $160^{\circ}$, allowing the measurement of the first 5 reflections from 110 to 310 of the steel specimens. In the case of the Philips $\mathrm{X}$ 'Pert diffractometer the instrumental pattern was measured by using a NIST SRM-660a $\mathrm{LaB}_{6}$ peak profile standard material.

\section{Results and discussion}

\subsection{Qualitative features of the diffraction patterns obtained by the high resolution $X$-ray diffractometer}

Typical grey scale IP readouts for the $154.530 \mathrm{~h}$ dry-steam pipe material are shown in Fig. 1 in the large angle region, i.e. from 95 to $168^{\circ}$ in $2 \theta$. For the sake of comparison the IP readout of a fine grain plastically deformed steel specimen (FGSS) is also shown in Fig. 1b. The IP readouts of the 310 Debye-Scherrer lines corresponding to the ISt, $154.530 \mathrm{~h}$, $220.384 \mathrm{~h}$ and FGSS specimens are shown in Fig. 2. Figures 1 and 2 indicate the following qualitative features: (1) The Debye-Scherrer lines corresponding to the dry-steam pipe materials are spotty, whereas the one corresponding to the FGSS specimen is smooth.

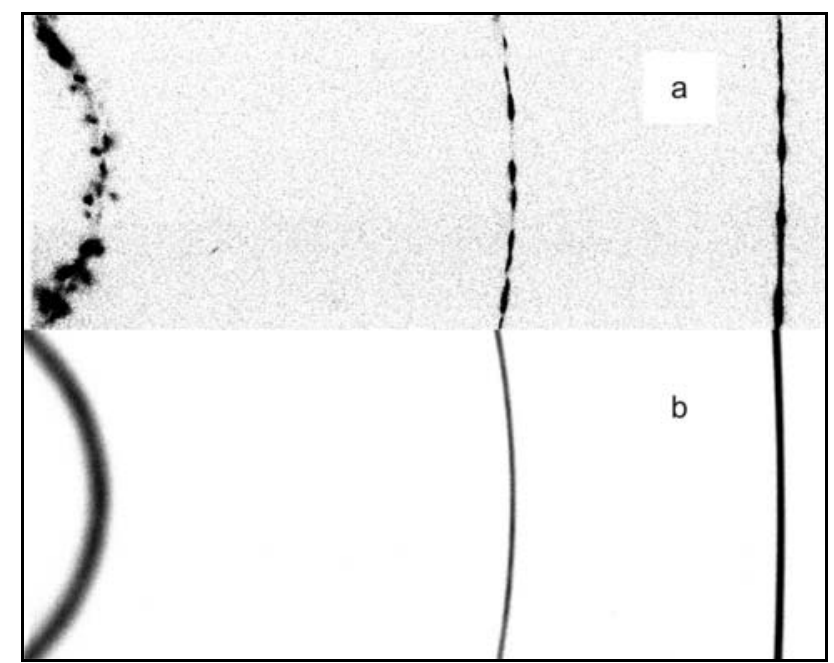

Fig. 1. Grey scale imaging plate (IP) readouts for the $154.530 \mathrm{~h}$ dry-steam pipe material (a) and a fine grain plastically deformed steel specimen (b). The IPs correspond to the large angle section of the diffraction patterns from 95 to $168^{\circ}$ in $2 \theta$, with the Debye-Scherrer ring sections of the 310,220 and 211 reflections, respectively. The IP in (b) is for the purpose of reference where diffraction spots of individual grains are not visible because of the fine grain size of the specimen.

(2) The spottiness is best observed in the patterns of the 310 lines, shown separately in Fig. 2. (3) The spots are somewhat diffuse for the ISt specimen, they become widely scattered for the $154.530 \mathrm{~h}$ specimen and seem to relax in the case of the $220.384 \mathrm{~h}$ specimen. (4) The spottiness indicates that the grains in the dry-steam pipe materials are large and that there are considerable intergranular, second-order residual internal stresses in the materials. (5) The qualitative inspection of Fig. 2 suggests that the intergranular residual internal stresses are largest in the $154.530 \mathrm{~h}$ specimen.

\subsection{Diffraction patterns obtained by the $\theta-2 \theta$ and the high resolution $X$-ray diffractometers}

The $\theta-2 \theta$ diffraction pattern measured in the $\mathrm{X}$ 'Pert (Philips) diffractometer is shown in Fig. 3a. The inset is the enlarged part of the spectrum in the large angle region. The figure shows that the diffraction profile is extremely narrow. The line profiles of the 110 reflection of the $220.384 \mathrm{~h}$ specimen and the 


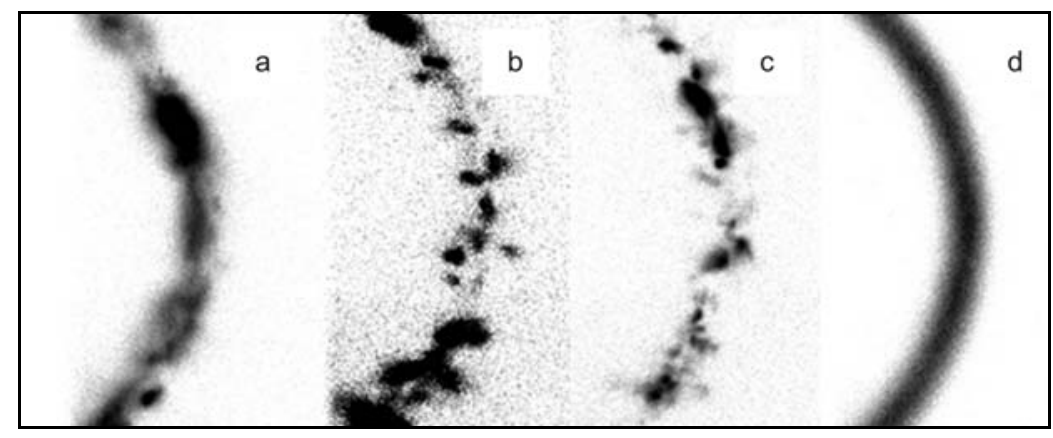

Fig. 2. IP readouts of the 310 Debye-Scherrer lines corresponding to the ISt (a), $154.530 \mathrm{~h}$ (b), $220.384 \mathrm{~h}$ (c) and a fine grain steel specimen $(\mathrm{d})$.
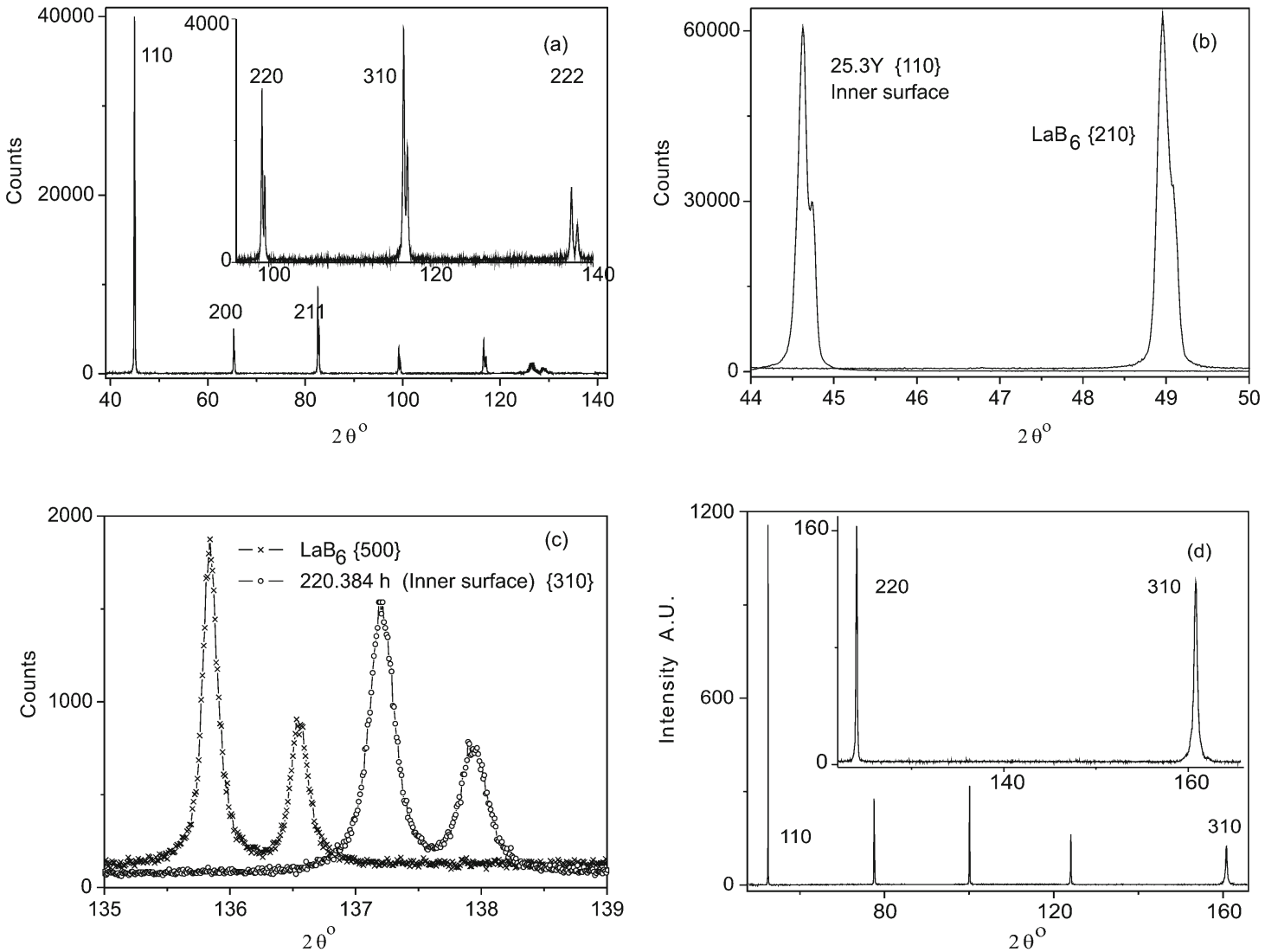

Fig. 3. Diffraction patterns measured in X'Pert (Philips) $\theta-2 \theta$ diffractometer. (a) Diffraction pattern corresponding to the $220.384 \mathrm{~h}$ inner-surface specimen. (b) Comparison of the 110 reflection of the $220.384 \mathrm{~h}$ inner-surface specimen with the 210 reflection profile of the $\mathrm{LaB}_{6}$ NIST SRM-660a standard specimen. (c) Comparison of the 310 reflection of the $220.384 \mathrm{~h}$ inner-surface specimen with the 500 reflection profile of the LaB 6 NIST SRM-660a standard specimen. (d) Diffraction pattern of the $220.384 \mathrm{~h}$ inner-surface specimen measured in the high resolution double crystal diffractometer with Co $\mathrm{K} \alpha_{1}$ radiation.

210 reflection of the NIST SRM-660a $\mathrm{LaB}_{6}$ standard material are shown together in Fig. 3b. The figure shows that $\mathrm{K} \alpha_{1}-\alpha_{2}$ splitting is clearer for the $220.384 \mathrm{~h}$ specimen than for the $\mathrm{LaB}_{6}$ standard material. This means that, at least in this angular range, the standard material has larger line broadening than the $220.384 \mathrm{~h}$ specimen. For this reason, quantitative line profile analysis cannot be carried out on the
X'Pert $\theta-2 \theta$ diffraction patterns, at least not by using the NIST SRM-660a $\mathrm{LaB}_{6}$ standard material for the instrumental effect. In the large angle range the situation is different. The line profiles of the 312 and the 500 reflections of the $220.384 \mathrm{~h}$ and $\mathrm{LaB}_{6}$ specimens are shown in Fig. 3c. The figure shows that in this angular range the line profiles of the steel specimen are slightly broader than those of the standard materials. 


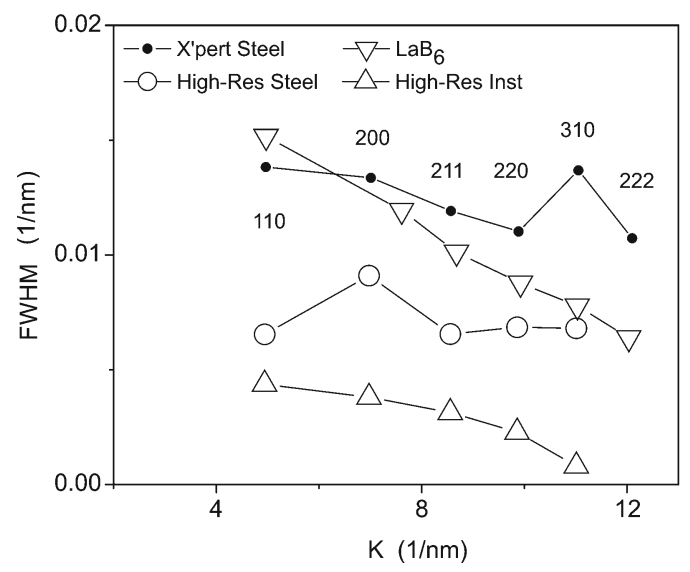

Fig. 4. Williamson-Hall plots of the measured FWHM (in $\mathrm{nm}^{-1}$ scales) corresponding to the diffraction patterns measured in X'Pert (Philips) $\theta-2 \theta$ diffractometer, $220.384 \mathrm{~h}$ inner-surface specimen (black dots), $\mathrm{LaB}_{6}$ NIST SRM-660a standard (open down triangles). FWHM values corresponding to the diffraction patterns measured in high-resolution double crystal diffractometer with Co $\mathrm{K} \alpha_{1}$ radiation (open circles). FWHM values corresponding to calculated Gaussian instrumental profiles for the high resolution double crystal diffractometer patterns (open up triangles), for details see the text.

A typical diffraction pattern measured in the special high resolution double crystal diffractometer is shown in Fig. 3d. Each peak in this pattern corresponds to the diffraction profile of one single diffraction spot in the IP shown in Figs. 1 and 2. More details about the evaluation of the IP data are given below. Note that, because of the Co radiation, only 5 reflections are measured here. For the sake of the qualitative clarification of line broadening effects in the dry-steam pipe steel materials, Williamson-Hall plots [7] of the FWHM are shown in Fig. 4. The figure shows that the FWHM values of the $220.384 \mathrm{~h}$ (full dots) and $\mathrm{LaB}_{6}$ (open down-triangles) X'Pert data are crossing each other, in correlation with the qualitative behaviour shown in Figs. 3a-c. Note that the FWHM values correspond always to the $\mathrm{K} \alpha_{1}$ components only. In the same figure the FWHM values measured in the high-resolution diffractometer (open circles) are considerably smaller than any values measured in the X'Pert diffractometer. Since, however, line broadening for the dry-steam pipe steel materials is so small, the instrumental effect in the present case cannot be neglected. Taking into account (i) the parallel beam geometry, (ii) the narrow spot size on the specimen, (iii) the pixel size of the IP, which is $50 \mu \mathrm{m}$ in the present case, and (iv) the spread function as 3 pixels on the IP, Gaussian instrumental profiles have been constructed numerically. The FWHM values of these instrumental profiles are also shown as open up-triangles in Fig. 4.

\subsection{Intergranular, second-order residual internal stresses}

For the evaluation of the intergranular, second-order residual internal stresses, the IP data are numerically divided into narrow, typically 11 parallel stripes, as shown schematically in Fig. 5. Integration along the Debye-Scherrer arcs is carried out within each stripe, providing $\theta-2 \theta$ intensity distribution patterns in which the peaks corresponding to individual grains can well be observed. Four and five typical patterns of the 310 reflections for the ISt, the $154.530 \mathrm{~h}$ and the $220.384 \mathrm{~h}$ specimens are shown in Figs. $6 \mathrm{a}-\mathrm{c}$, respectively. The average position of the 310 reflection in all three states of the specimen is $2 \theta_{\mathrm{av}}=160.95^{\circ}$. The shifts of peaks or shoulders corresponding to individual grains, relative to $2 \theta_{\text {av }}$, are caused by the grain-to-grain, intergranular, second-order residual internal stresses. The positions of the peaks and/or shoulders have been evaluated numerically for as many peaks and shoulders as possible for the three states and for the inner and outer surface parts of the dry-steam pipe materials. The histograms of the frequencies of peak/shoulder positions around $2 \theta_{\text {av }}$ for the three different outer surface specimens are shown in Fig. 7. The

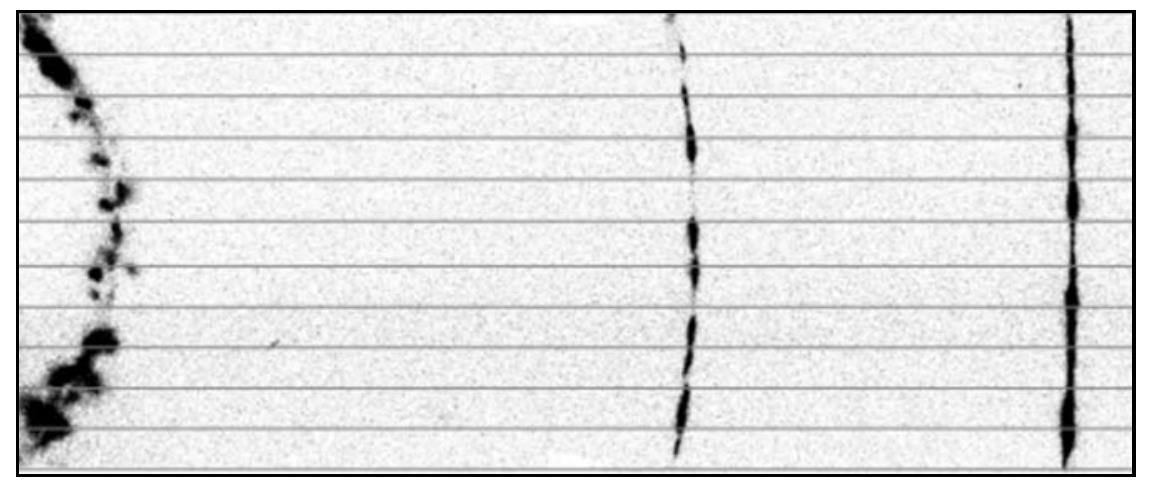

Fig. 5. Schematic drawing of the division of IPs into narrow, typically 11, parallel stripes for the purpose of evaluating the grain-to-grain residual internal stresses. 

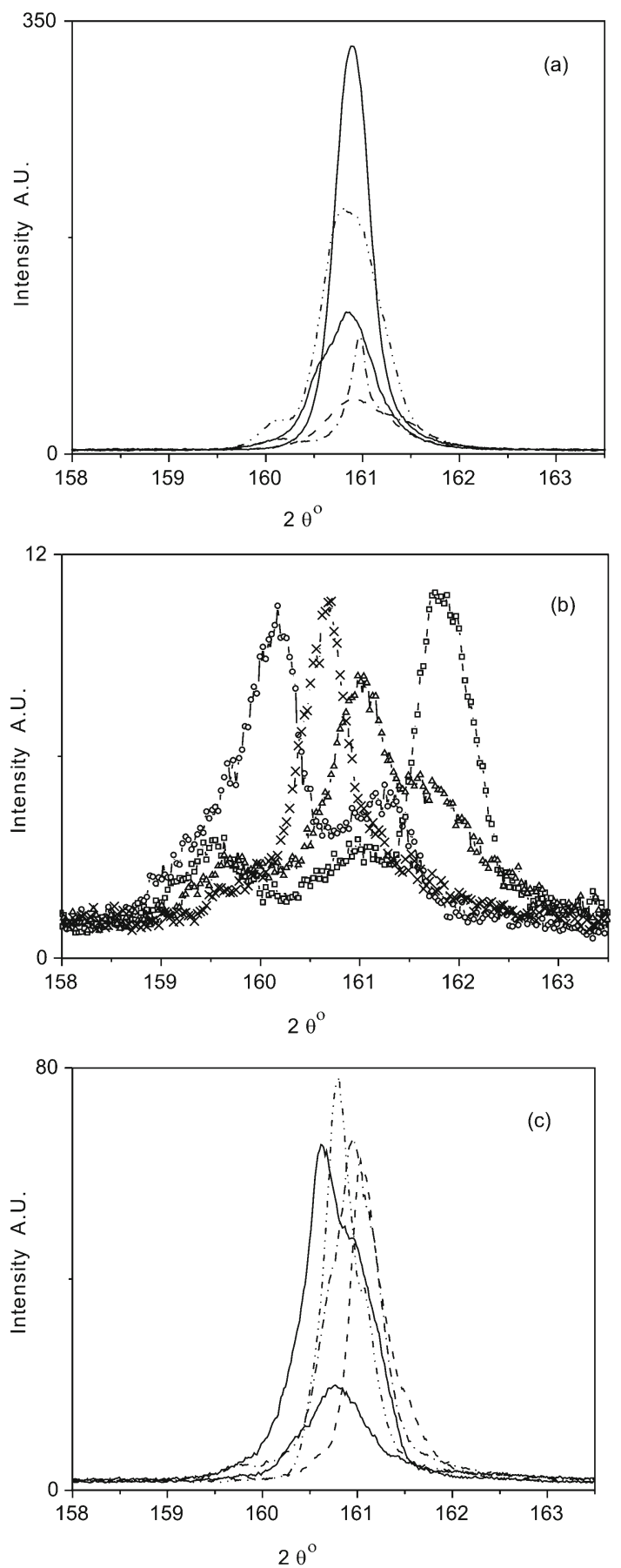

Fig. 6. Typical patterns of the 310 reflections corresponding to individual grains in the specimens, for the ISt (a), the $154.530 \mathrm{~h}$ (b) and the $220.384 \mathrm{~h}$ (c) specimens, respectively.

solid curves in the figures are fitted Gaussian curves to the measured histograms. The widths (or the variance) of these fitted Gaussian curves are considered as the measure of the intergranular, second-order residual internal stresses: $\Delta \sigma_{\text {meas }}$. The instrumental ef-
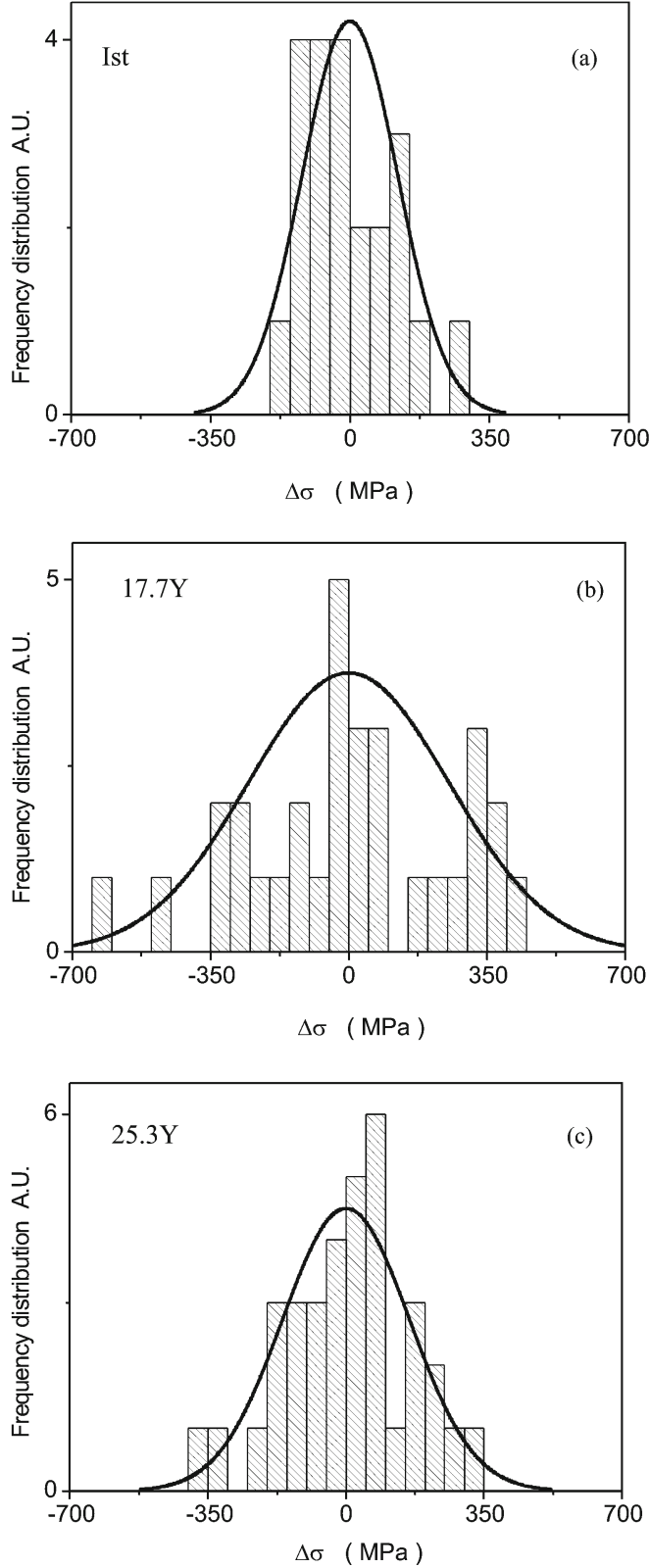

Fig. 7. Typical histograms of the frequencies of peak or shoulder positions around the average positions of the 310 diffraction peaks, $2 \theta_{\text {av }}$, for the three different outer surface ISt (a), the $154.530 \mathrm{~h}$ (b) and the $220.384 \mathrm{~h}$ (c) specimens, respectively.

fect causing an uncertainty in the residual stress measurements is: $\Delta \sigma_{\text {uncert }} \cong \pm 50 \mathrm{MPa}$. This is taken into account by subtracting an offset of $\Delta \sigma_{\text {offset }}=2 \times$ $\Delta \sigma_{\text {uncert }}=100 \mathrm{MPa}$ from the measured, $\Delta \sigma_{\text {meas }}$, average stress values. The differences between the measured and offset values are considered as the true intergranular, second-order residual internal stresses: $\Delta \sigma_{\mathrm{II}}=\Delta \sigma_{\text {meas }}-\Delta \sigma_{\text {offset }}$, prevailing in the dry-steam pipe materials after unloading and cooling to room temperature. These values are plotted in Fig. 8 as a 


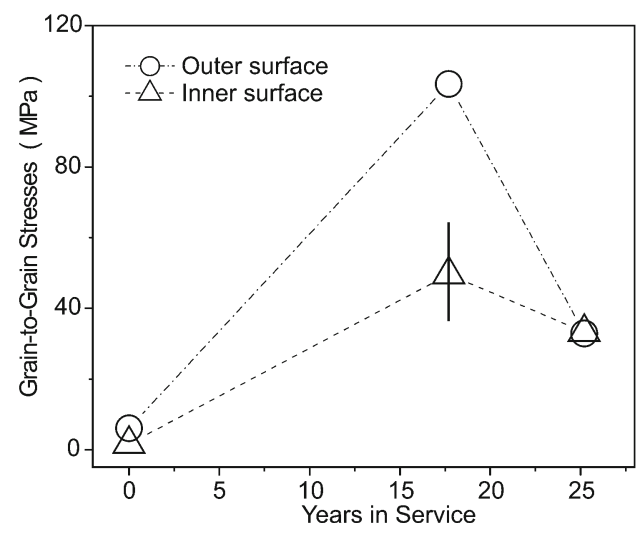

Fig. 8. The true intergranular, grain-to-grain, second-order residual internal stresses: $\Delta \sigma_{\mathrm{II}}$, prevailing in the dry-steam pipe materials after unloading and cooling to room temperature as a function of service period. The connecting lines are only to guide the eye.

function of service periods for the inner and outer surfaces of the dry-steam pipe materials.

\subsection{The origin of intergranular, second-order residual internal stresses}

As stated in the introduction, the initial state of the materials was prepared by normalizing from $950-980{ }^{\circ} \mathrm{C}$ and tempering at $720-750{ }^{\circ} \mathrm{C}$, and slow cooling in air to room temperature. The purpose of this treatment is to anneal out all kinds of internal stresses from the materials. The X-ray data presented in Figs. 4a and 8 show an evidence that the ISt of the materials, within experimental error, is exceedingly strain or stress free. After $154.530 \mathrm{~h}$ in service, however, large grain-to-grain, second order residual internal stresses develop, as is clearly evidenced by Figs. 2, 4b and 8, respectively. The evolution of these second order stresses, $\Delta \sigma_{\mathrm{II}}$, is explained as follows. The present steel has a strong elastic anisotropy. The elastic constants are: $c_{11}=231.4, c_{12}=134.6$ and $c_{44}=116.4 \mathrm{GPa}[8]$, from which the Zener constant is: $A_{\mathrm{Z}}=2 c_{44} /\left(c_{11}-c_{12}\right)=2.51$. The largest and smallest Young's moduli are: $E_{001}=132.4 \mathrm{GPa}$ and $E_{111}=283.3 \mathrm{GPa}$ [9], respectively. Under service conditions at $540{ }^{\circ} \mathrm{C}$ at a pressure of 165 bar the operational tearing stresses are $\sigma_{\mathrm{T}} \cong 70 \mathrm{MPa}$. Elastic anisotropy, especially the large difference in the values of Young's modulus render the materials to follow Masing's behaviour [9]. The grain orientation is sorted by the direction of the tearing stress, $\sigma_{\mathrm{T}}$. Grains oriented with [001] or [111] parallel (or close to parallel) with $\sigma_{\mathrm{T}}$, respond as soft or hard grains, respectively. The stress-strain response of the two types of grains is shown schematically in Fig. 9. The heavy solid and dashed lines are the stress-strain responses of the hard and soft oriented grains with $E_{111}$ and $E_{001}$

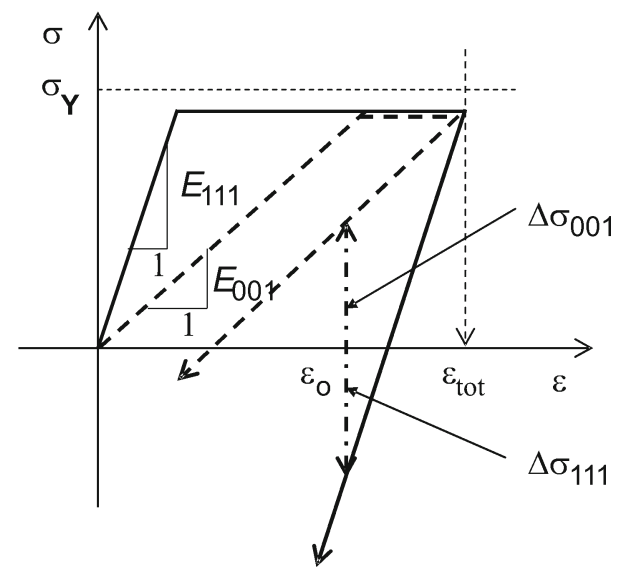

Fig. 9. Schematic stress strain response of two types of grains with large and small Young's moduli, $E_{111}$ and $E_{001}$, respectively. The heavy solid and dashed lines are the stress-strain response of these two types of grains. $\varepsilon_{\text {tot }}$ is the total strain, whereas $\varepsilon_{0}$ is the residual strain after unloading, i.e. the strain corresponding to stress equilibrium after unloading and cooling. $\Delta \sigma_{001}$ and $\Delta \sigma_{111}$ are the schematic forward and backward residual internal stresses remaining and acting between the two grain types after unloading and cooling.

Young's moduli, respectively. Since the deformation process in the present case is elastic plus creep below the yield stress $\sigma_{\mathrm{Y}}$, the $\sigma-\varepsilon$ response is shown below $\sigma_{\mathrm{Y}}$. For simplicity it is assumed that the two grain types are strained in parallel up to $\varepsilon_{\text {tot }}$. The more exact treatment would need the self-consistent elastic-plastic descriptions, that, however, would provide the same qualitative conclusions. After cooling and unloading the remaining strain, $\varepsilon_{0}$ is determined by stress equilibrium between the forward, $\Delta \sigma_{001}$, and backward, $\Delta \sigma_{111}$, grain-to-grain, second-order residual internal stresses. In the simple model presented here it is assumed that the two different grain types yield approximately at the same stress. This is most probably true since the present material, at least in its initial state, is a strain and stress free precipitation hardened creep resistant steel.

The decrease of $\Delta \sigma_{\mathrm{II}}$ from $154.530 \mathrm{~h}$ to $220.384 \mathrm{~h}$ of service is explained in the following way. For the formation of $\Delta \sigma_{\mathrm{II}}$ it is assumed that during cooling and unloading the two different, hard and soft types of grains, strain each other without any grain boundary sliding between them. This mechanism presumes that the grain boundaries are strong sites in the materials holding adjacent grains firmly together. In the last state, i.e. after $220.384 \mathrm{~h}$ in service, however, the material reaches close to the end of the stationary creep state. There is TEM evidence for precipitate coarsening at the grain boundaries, which is most probably accompanied by some void formation, also along the grain boundaries. Two typical TEM micrographs cor- 

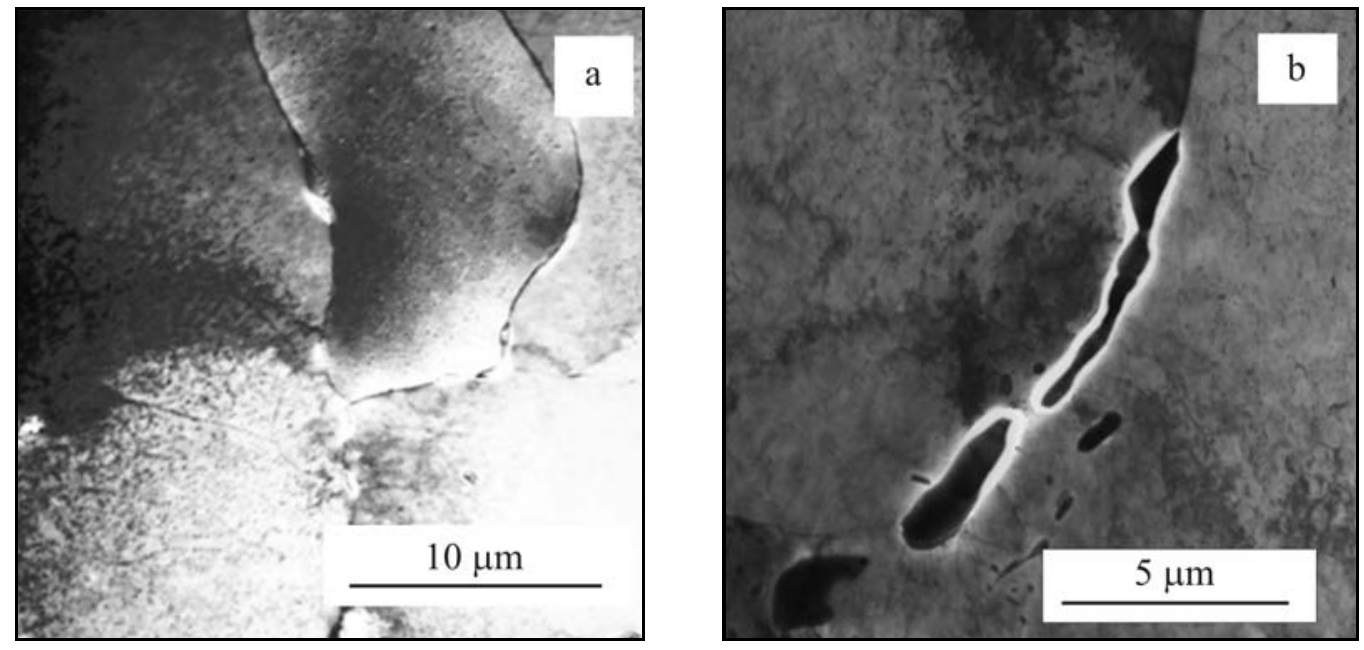

Fig. 10. Typical TEM micrographs showing the grain boundary structure in the ISt (a) and the $220.384 \mathrm{~h}$ (b) specimens, respectively.

responding to the states after $154.530 \mathrm{~h}$ and $220.384 \mathrm{~h}$ of service are shown in Figs. 10a and 10b, respectively. These two processes, i.e. precipitation coarsening along the grain boundaries and void formation also mainly along grain boundaries, are a consequence of creep deterioration, which destroys grain boundary adherence. Deterioration of grain boundary structure allows for grain boundary sliding or slip, which relaxes the magnitude of $\Delta \sigma_{\mathrm{II}}$, as shown in Figs. 6c and 8. Exactly the same argument can be used to understand the relatively large difference between the $\Delta \sigma_{\text {II }}$ values after $154.530 \mathrm{~h}$ in service in the inner and outer surface regions of the steam pipe, i.e. $\Delta \sigma_{\mathrm{II}, \mathrm{IN}} \cong 45 \mathrm{MPa}$ and $\Delta \sigma_{\mathrm{II}, \mathrm{OUT}} \cong 110 \mathrm{MPa}$, respectively. The deterioration of grain boundary adherence in the present case is most probably a diffusion controlled creep process. The outer surface region of the pipe operates at a lower temperature than the inner surface. As a consequence, the inner surface is somewhat ahead of the outer surface, as far as the creep process is concerned. After $220.384 \mathrm{~h}$ service, both the inner and outer surfaces are close to the end of the stationary creep life of the materials. In this latter case, grain boundary adherence has deteriorated to such an extent that only a reduced amount of $\Delta \sigma_{\text {II }}$ remains in the pipe materials after cooling and unloading.

\section{Conclusions}

Dry steam pipe steel materials operating in fossil power plants are exceedingly strain free in the initial state. After about $150.000 \mathrm{~h}$ in service, which is of about $2 / 3$ of the expected lifetime, large grain-to-grain second-order residual internal stresses are built up in the material. These internal stresses develop as a consequence of elastic anisotropy of iron and the Masing behaviour of polycrystalline materials.
The internal stresses are evolving at the temperature and under the stress acting during service, however, they can be observed and measured after unloading and cooling to ambient temperatures. Closer to the end of the expected lifetime of the materials, after about $220.000 \mathrm{~h}$ in service, the grain-to-grain internal stresses are strongly reduced. Reduction of these internal stresses is an indication of the deterioration of grain boundary structures by precipitation coarsening and void formation along grain boundaries.

\section{Acknowledgements}

T. U. is grateful to the Hungarian National Science Foundation, OTKA \#67692 and \#71594 for supporting this work.

\section{References}

[1] PATERSON, I. R.-WILSON, J. D.: Int. J. Pressure Vessels Piping, 79, 2002, p. 541.

[2] SINGH, R.-SINGH, S. R.: Int. J. Pressure Vessels Piping, 73, 1997, p. 89.

[3] SUNA, W.-HYDE, T. H.-BECKER, A. A.-WILLIAMS, J. A.: Int. J. Pressure Vessels Piping, 77, 2000, p. 389.

[4] SKLENIČKA, V.-KUCHAŘOVÁ, K.-SVOBODA, M.-KLOC, L.-BURŚIK, J.-KROUPA, A.: Mater. Characterization, 51, 2003, p. 35.

[5] WILKENS, M.-ECKERT, H. Z.: Naturforsch., 19a, 1964, p. 459.

[6] UNGÁR, T.-TÓTH, L. S.-ILLY, J.-KOVÁCS, I.: Acta Metall., 34, 1986, p. 1257.

[7] WILliAMSON, G. K.-HALL, W. H.: Acta Metall., 1, 1953, p. 22.

[8] RotTeR, C. A.-SMith, C. S.: J. Phys. Chem. Solids, 27, 1966, p. 267.

[9] MASING, G.: In: Proc. 2nd Inst. Congr. Appl. Mechanics, 1926, p. 332. 